\title{
Model Pendidikan Islam Progresif
}

\author{
${ }^{1}$ Muh. Idris; ${ }^{2}$ Sabil Mokodenseho \\ ${ }^{1}$ Institut Agama Islam Negeri Manado, Indonesia \\ 2Sekolah Pascasarjana Universitas Islam Negeri Syarif Hidayatullah Jakarta, Indonesia \\ 1idristunru02@gmail.com; 2sabil.mokodenseho@gmail.com
}

\begin{abstract}
Islamic education is a future choice, and a reference in developing human potential and the embryo of world civilization. However, Islamic education does not always run smoothly, and in fact, it seems static because the education that is carried out cannot be separated from the system and the laws of life that take place. Therefore, Islamic education must be managed in a professional and quality manner. This paper aims to offer a progressive Islamic education model. Through literature studies from various literatures, which are then described and analysed with a qualitative approach, it shows that the Islamic education model must be designed and oriented towards empowering and developing human potential, so as to produce competitive and productive Human Resources. The basic models and styles of progressive Islamic education are able to create positive forces that can influence and determine human attitudes in life. The stronger the quality and potential of the human person, the more they will be able to have a visionary perspective and be able to realize and deepen the meaning of Islamic education in life as a determinant of identity. Thus, the Islamic education system will immediately be reformulated in accordance with the dynamics of the times, market needs, and based on local wisdom.
\end{abstract}

Keywords. Progressive Islamic Education; Empowerment; Development; Competitive; Productive

\begin{abstract}
Abstrak. Pendidikan Islam menjadi pilihan masa depan, dan rujukan dalam mengembangkan potensi manusia dan cikal bakal peradaban dunia. Namun, pendidikan Islam tidak selalu berjalan dengan mulus, dan bahkan, terkesan statis sebab pendidikan yang dijalankan tidak dapat dilepaskan dari sistem dan hukum kehidupan yang berlangsung. Oleh karenanya, pendidikan Islam harus dikelola secara profesional dan berkualitas. Tulisan ini bertujuan untuk menawarkan model pendidikan Islam progresif. Melalui studi kepustakaan dari berbagai literatur, yang kemudian dideskripsikan dan dianalisis dengan pendekatan kualitatif, menunjukkan bahwa model pendidikan Islam harus didesain dan berorientasi pada pemberdayaan dan pengembangan potensi manusia, sehingga menghasilkan Sumber Daya Manusia yang kompetitif dan produktif. Model dan corak dasar pendidikan progresif mampu menciptakan kekuatan-kekuatan positif yang bisa memengaruhi dan menentukan sikap manusia dalam kehidupannya. Semakin kuat kualitas dan potensi pribadi manusia, maka mereka semakin bisa memiliki cara pandang visioner, serta mampu menyadari dan mendalami makna pendidikan Islam dalam kehidupan sebagai penentu jati diri. Dengan demikian, sistem pendidikan Islam segera dirumuskan kembali sesuai dengan dinamika zaman, kebutuhan pasar, dan berbasis kearifan lokal.
\end{abstract}

Kata Kunci. Pendidikan Islam Progresif; Pemberdayaan; Pengembangan; Kompetitif; Produktif

Copyright (C) J-PAI: Jurnal Pendidikan Agama Islam. All Right Reserved.

This is an open-access article under the CC BY-SA license

(https://creativecommons.org/licenses/by-sa/4.0/).

Correspondence Address: jpai@uin-malang.ac.id 


\section{A. PENDAHULUAN}

Pendidikan Islam merupakan salah satu disiplin ilmu keislaman yang memiliki daya tarik sendiri untuk dikaji. Tidak heran, ia selalu hangat untuk dibicarakan, terutama oleh kalangan akademisi. Sebab, pendidikan Islam sejatinya memiliki andil besar dalam rangka membina manusia secara utuh dan seimbang, baik dari aspek rohani maupun jasmani (Mansir \& Karim, 2020; Bashori et al., 2020). Idealnya, pendidikan Islam berusaha mengantarkan manusia mencapai keseimbangan hidup secara menyeluruh melalui latihanlatihan kejiwaan, akal pikiran, kecerdasan, perasaan ataupun panca indra (Abd, 2020; Akbar et al., 2020). Pendidikan Islam juga berupaya mengembangkan semua aspek dalam kehidupan manusia, meliputi spiritual, intelektual, imajinasi, dan keilmiahan, baik secara individu maupun kelompok menuju kebaikan dan pencapaian kesempurnaan hidup. Kesempurnaan yang dimaksud adalah bagaimana ia memosisikan diri dalam hubungannya dengan Tuhan, alam semesta maupun sesama manusia (Anam \& Fikroni, 2020; Manan, 2020).

Azis (2016) mengemukakan bahwa pendidikan Islam adalah suatu proses spiritual, akhlak, intelektual dan sosial yang berusaha membimbing manusia, baik individu maupun kelompok. Selain itu, pendidikan Islam bisa membimbing manusia, memberi nilai dan prinsip-prinsip, serta teladan ideal dalam kehidupan yang bertujuan untuk mempersiapkan kehidupan di dunia dan akhirat (Azman \& Helandri, 2020; Rabilla \& Nurhayati, 2020). Kaitannya dengan peserta didik, pendidikan Islam adalah suatu upaya untuk mengembangkan dan mengarahkan anak didik supaya dapat menjadi manusia masa depan yang ideal. Salah-satu cara untuk mencapai hal tersebut adalah menjadikan anak didik sebagai manusia yang lebih lengkap dalam dimensi religiusnya. Suatu proses pengkondisian sangat diperlukan agar anak didik menjadi lebih memahami dan mengimani, serta mengamalkan agamanya sebagai sebuah ajaran yang menjadi pandangan dan pedoman hidup manusia (Fajariah \& Suryo, 2020; Suminto, 2019).

Dengan begitu, pendidikan benar-benar merupakan latihan fisik, mental dan moral bagi tiap-tiap individu agar mereka menjadi manusia berbudaya, mampu menunaikan fungsi dan tugas sebagai khalifah, serta berhasil mewujudkan kebahagiaan di dunia dan akhirat (Ibrahim, 2019; Lafmejani, 2020). Pendidikan adalah sebuah proses pembentukan karakter manusia (Kotsonis, 2020; Gunawan et al., 2020) yang tidak pernah berhenti, guna meningkatkan harkat dan martabat manusia yang berlangsung sepanjang hayat (Paulussen \& Scheinin, 2019; Ulgen, 2020; Okros, 2020).

Meskipun pendidikan Islam dalam sejarahnya memiliki andil besar membina pribadi manusia yang utuh dan seimbang, baik dari aspek jasmani maupun rohani. Namun, baik pendidikannya maupun lembaga pendidikan yang dijalankan, tidak selalu berjalan dengan mulus, atau dalam arti lain, memiliki kelemahan-kelemahan. Dari sisi pendidikannya, pola pengetahuan tradisional yang diajarkan tidak cukup untuk menjawab tantangan zaman sebagaimana temuan penelitian Abdullah (2017) bahwa pola tersebut mengalami kesulitan luar biasa ketika harus menghadapi perkembangan sejarah umat manusia secara global dengan dinamika, tantangan baru, persaingan dan konflik, baik lokal, regional, nasional, maupun internasional. Terlebih lagi, ketika harus menghadapi gagasan kemajuan. Sementara dari sisi pengelolaan lembaga pendidikan Islam, penelitian Fahriana dan Huda (2019) mengungkapkan beberapa faktor kelemahan pengelola pendidikan Islam, yaitu; lemahnya sumber daya manusia di lembaga pendidikan Islam; sarana dan prasarana yang masih terbatas pada sarana wajib; lembaga pendidikan Islam umumnya kurang mampu menangkap peluang, sehingga mereka hanya puas dengan kondisi yang dihadapi saat ini; output lembaga pendidikan Islam belum sepenuhnya dapat bersaing dengan lulusan lembaga pendidikan lain dan sebagainya. Selain itu, temuan riset Das et al., (2016) juga mengungkapkan bahwa kendala berat yang akan dihadapi lulusan pendidikan Islam, 
yaitu akselerasi global yang berimplikasi pada daya saing, individualisme, sekularisme, materialisme, dan sebagainya.

Beberapa kelemahan di atas, menandakan bahwa masih banyak kendala yang dihadapi dalam berbagai sisi pendidikannya saat ini, dan kendala yang akan dihadapi kemudian. Ini harus disikapi secara serius karena tidak jarang kendala-kendala tersebut membuatnya statis, atau bahkan membuatnya mundur, sebab pendidikan yang dijalankan tidak dapat dilepaskan dari sistem dan hukum kehidupan yang sudah ada sejak lama dan terus berlangsung hingga hari ini.

Pendidikan Islam telah dibentuk oleh alasan sejarah, sosial, dan budaya, serta politik dan sebagainya, namun sistem pendidikannya, secara mandiri, belum secara maksimal membawa pembangunan bagi masyarakat. Oleh karena itu, pendidikan Islam harus progresif. Untuk itu, tulisan ini bertujuan untuk menawarkan model pendidikan Islam progresif, yang menekankan pada pengembangan potensi kualitas Sumber Daya Manusia.

\section{B. METODE}

Penelitian ini termasuk jenis penelitian kepustakaan (library research), yaitu jenis penelitian yang cara mendapatkan data informasi atau sumber datanya adalah dengan melalui literatur berupa buku, artikel jurnal dan sejenisnya (Mann, 2015; Jackson, 2015; Watts \& Mahfood, 2014). Sumber data yang digunakan dalam kaitannya dengan pendidikan Islam, di antaranya adalah "Islam dan Dinamika Kebebasan Akademi" (Fadjar, 1983), "Pengembangan Pendidikan Islam yang Menjanjikan Masa Depan" (Fadjar, 2006), Pendidikan Islam di Perguruan Tinggi (Fadjar \& Ghofir, 1981), Pengantar Filsafat Pendidikan Islam (Marimba, 1989), Pendidikan Islam Tradisi dan Modernisasi Menuju Milenium (Azra, 1999) dan Paradigma Baru Pendidikan Nasional Rekonstruksi dan Demokratisasi (Azra, 2002), Falsafat al-Tarbiyah al-Islamiyah (Al-Kailani, 1988), AlTarbiyah al-Islamiyah wa Falsafatuha (Al-Abrasyi, 1969), New Horizons in Muslim Education (Ashraf, 1985), dan Ushul al-Tarbiyah al-Islamiyah fi al-Bait wa al-Madrasah wa al-Mujtama' (Al-Nahlawi, 1996). Selain buku, digunakan juga beberapa artikel jurnal berjudul "Islamic Education and Human Construction in The Quran" (Abdullah et al., 2019), "Swot Analysis of Islamic Education Facing the Era of Globalization" (Buto \& Hafifuddin, 2019), dan "A Step Ahead Education (Human Potential Development Oriented)" (Azis, 2016), serta beberapa literatur pendukung lainnya.

Data yang diperoleh melalui beberapa literatur di atas, diolah menggunakan metode deskriptif analitis dengan pendekatan kualitatif. Model penelitian ini berupaya mendeskripsikan, menganalisa, dan menginterpretasikan data-data yang tersedia, kemudian membuat simpulan (Kalaian et al., 2019; Flick, 2018; Ahmadi, 2017; Merriam \& Tisdell, 2016). Dengan demikian, penelitian ini diharapkan dapat memberi masukan kepada lembaga pendidikan Islam terkait model pendidikan Islam progresif.

\section{HASIL DAN PEMBAHASAN}

\section{Pendidikan Islam: Definisi dan Konsep}

Merujuk pada sejarah pendidikan Indonesia maupun dalam studi kependidikan, sebutan pendidikan Islam umumnya dipahami sebatas sebagai "ciri khas" jenis pendidikan yang berlatar belakang keagamaan. Demikian pula batasan yang ditetapkan dalam UndangUndang Nomor 2 Tahun 1989 tentang Sistem Pendidikan Nasional (Mahfud, 2020; Abdullah, 2019; Suri et al., 2019). Batasan yang sama juga terdapat dalam Undang-Undang Nomor 20 Tahun 2003 tentang Sistem Pendidikan Nasional. Zarkowi Soejoeti sebagaimana dikutip Fadjar (2006) mengatakan pendidikan Islam paling tidak mempunyai tiga pengertian. Pertama, lembaga pendidikan Islam itu, dari segi pendirian dan 
penyelenggaraannya didorong oleh hasrat mengejawantahkan nilai-nilai Islam yang tercermin dalam nama lembaga pendidikan dan kegiatan-kegiatan yang diselenggarakan. Dalam pengertian ini Islam dilihat sebagai sumber nilai yang harus diwujudkan dalam kehidupan lembaga pendidikan yang bersangkutan. Kedua, lembaga pendidikan yang memberikan perhatian pada penyelenggaraan kajian keislaman yang tercermin dalam program kajian sebagai ilmu dan diperlakukan sebagaimana ilmu-ilmu lain, yang menjadi program kajian lembaga pendidikan Islam bersangkutan. Ketiga, mengandung dua pengertian sebelumnya dalam arti lembaga tersebut memperlakukan Islam sebagai sumber nilai bagi sikap dan tingkah laku yang harus tercermin dalam penyelenggaraannya maupun sebagai bidang kajian yang tercermin dalam program kajiannya.

Konsep pendidikan Islam sebagaimana yang dikemukakan Soejoeti di atas, meskipun belum memadai secara falsafi untuk disebut sebagai pendidikan Islam, tetapi setidaknya dapat dijadikan sebagai pengantar dalam memahami pendidikan Islam secara lebih mendasar. Berdasarkan pengertian tersebut, keberadaan pendidikan Islam tidak sekedar menyangkut persoalan ciri khas, melainkan lebih mendasar pada tujuan yang diidamkan dan diyakini sebagai yang paling ideal, yaitu insan kamil atau Muslim paripurna (Setiawan, 2020). Orientasi pendidikan Islam sekaligus mempertegas bahwa misi dan tanggungjawab yang diemban pendidikan Islam lebih berat lagi. Dalam pembicaraan ini, jenis dan pengertian pendidikan Islam mencakup ketiga-tiganya, karena memang ketigatiganya itu adalah yang selama ini tumbuh dan berkembang di dunia termasuk Indonesia, serta telah menjadi bagian yang tidak terpisahkan dari sejarah maupun kebijakan pendidikan secara Nasional. Bahkan, dalam konteks Indonesia, tidak berlebihan kalau secara politis dikatakan bahwa kehadiran dan keberadaannya merupakan bagian dari andil umat Islam dalam perjuangan maupun dalam mengisi kemerdekaan.

Pendidikan Islam pada dasarnya tidak dapat dilepaskan dari Islam itu sendiri. Azra (2002) mengatakan Islam memuat beberapa aspek penting, di antaranya: aspek disiplin, kerja keras, keadilan, demokrasi, musyawarah, HAM, perdamaian dan semacamnya. Dari beberapa aspek tersebut, orang Islam percaya bahwa Islam adalah rahmatan lil alamin. Oleh karena itu, pendidikan Islam bertujuan menciptakan insan kamil. Terbinanya kepribadian Muslim atau insan kamil yang merupakan ketetapan tujuan pendidikan Islam masih merupakan idea statis, namun kualitas nilainya dinamis dan terus berkembang. Tujuan pendidikan Islam itu sarat dengan nilai-nilai fundamental memungkinkan terwujudnya kepribadian Muslim, yakni kondisi fisik dan mentalnya merupakan satu kesatuan secara terpadu. Sehingga dalam penampilan dan kegiatannya, tidak terjadi dikotomi antara jasmani dan rohani, serta dikotomi antara duniawi dan ukhrawi (Setiawan, 2020).

Sementara menurut Hamka (1962) untuk membentuk peserta didik yang memiliki kepribadian paripurna, maka eksistensi pendidikan agama Islam merupakan sebuah keharusan untuk diajarkan di sekolah-sekolah, termasuk sekolah umum. Namun, dalam tataran operasional, prosesnya tidak hanya dilakukan sebatas mentransfer ilmu pengetahuan saja, tetapi jauh lebih penting adalah bagaimana ilmu yang mereka peroleh mampu membuahkan suatu sikap yang baik sesuai dengan pesan nilai dan ilmu yang dimilikinya. Pendidikan bukan berarti hanya berorientasi pada hal-hal yang bersifat metafisik belaka. Dalam melaksanakan tugasnya sebagai khalifah fi al-ardl, manusia juga memerlukan pendidikan yang bersifat material. Hanya dengan pendekatan kedua proses tersebut manusia akan dapat melaksanakan tugas dan fungsinya di muka bumi ini dengan sebaik-baiknya. Berkaitan dengan tujuan pendidikan Islam, Hamka (1962) menyatakan bahwa pendidikan Islam bertujuan mengenal dan mencari keridaan Allah SWT., membangun budi pekerti untuk berakhlak mulia, serta mempersiapkan peserta didik untuk hidup secara layak dan berguna di tengah masyarakat luas. 


\section{Pendidikan Islam dalam Membentuk Kepribadian Muslim}

Pada dasarnya, tujuan pendidikan Islam adalah untuk mencapai derajat menuju iman dan takwa kepada Allah SWT. Dalam proses pencapaian tersebut, didasarkan pada materi pembelajaran, jam pelajaran dan metode penyampaiannya (Wekke \& Mokodenseho, 2017), sedangkan target yang ingin dicapai adalah untuk membentuk insan kamil. Sementara al-Ghazali sebagaimana dikutip Sheikh dan Ali (2019) mengatakan tujuan pendidikan Islam tercermin dalam dua segi, yaitu: insan purna yang bertujuan mendekatkan diri kepada Allah SWT., dan insan purna yang bertujuan mendapatkan kebahagiaan hidup di dunia dan di akhirat. Kebahagiaan di dunia dan akhirat dalam pandangan al-Ghazali adalah menempatkan kebahagiaan dalam proporsi yang sebenarnya. Kebahagiaan yang lebih memiliki nilai universal, abadi, dan lebih hakiki itulah yang diprioritaskan (Bensaid \& Machouche, 2020; Sugiana, 2019).

Terbinanya kepribadian Muslim tersebut menurut Fadjar nampak pada diri KH. Ahmad Dahlan (1868-1923) yang mencita-citakan pendidikan yang memberikan kedamaian dan diselenggarakan dengan baik budi dalam agama, luas pandangan dan bersedia berjuang untuk kemajuan masyarakat. Dengan perkataan lain bahwa perwujudan pendidikan Islam K.H. Ahmad Dahlan mengacu pada tiga matra yang saling terkait, yaitu: pertama, tauhid yang akan mendudukkan harkat manusia sebagai insan ahsani taqwim, punya daya tahan terhadap segala ujian hidup dan siap memihak kepada kebenaran. Kedua, jiwa dan pandangan hidup Islam yang akan membawa cita rahmatan lil alamin. Ketiga, kemajuan yang akan menempatkan manusia hidup kreatif.

Tiga matra sebagaimana disebutkan di atas sifatnya masih normatif. Oleh karena itu, masalah yang dihadapi adalah bagaimana memfungsikan yang normatif ini sehingga berhasil guna sebagai self-realization maupun pemberi jawaban terhadap realita hidup dan kehidupan kini serta mendatang dalam perolehan duniawi dan ukhrawi yang hasanah.

Al-Abrasyi (1969) dalam kajiannya tentang pendidikan Islam menyimpulkan lima tujuan yang asasi dalam pendidikan Islam, yaitu untuk membantu pembentukan akhlak yang mulia; mempersiapkan kehidupan dunia dan akhirat; persiapan untuk mencari rezeki dan menjaga kemaslahatan; menumbuhkan roh ilmiah pada anak didik dan memenuhi rasa keingintahuannya; serta memungkinkan untuk mengkaji berbagai ilmu dan menyiapkan anak didik untuk menguasai profesi tertentu. Di samping itu, melalui pendidikan, seseorang dimungkinkan dapat mengenal diri dan alam sekitarnya (Alayoubi et al., 2020).

Mahmood (2019) menyatakan bahwa tujuan pendidikan terkait dengan pandangan hidup. Jika pandangan hidupnya adalah Islam, maka tujuan pendidikan harus dari ajaran Islam. Senada dengan Mahmood, Al-Attas berpandangan tujuan pendidikan Islam adalah tercapainya manusia yang baik (Lovat, 2020; Lisaldi \& Lisa, 2019). Sementara Marimba (1989) mengatakan tujuan pendidikan Islam adalah terbentuknya kepribadian Muslim. Melalui pendidikan Islam, akan terwujud keseimbangan dalam diri seseorang dalam bentuk pemenuhan kebutuhan badan, jiwa, pikiran, dan perbuatan yang nantinya akan melahirkan akhlak yang mulia, kasih sayang, dan perasaan tolong menolong di antara sesama manusia (Mokodenseho \& Wekke, 2017; Yahya \& Rahmat, 2019).

Pendidikan Islam harus berorientasi pada kelangsungan eksistensi manusia dan juga peningkatan harkat kemanusiaan (Al-Kailani, 1988). Menurut Al-Nahlawi (1996) tujuan pendidikan Islam adalah pembebasan dan penyelamatan anak didik. Sehingga ia dapat mengenal agama, baik secara teori maupun praktiknya. Sementara Muhammad Abduh sebagaimana dikutip Syukri (2019) menjelaskan tujuan pendidikan adalah mendidik akal dan jiwa dan menyampaikannya kepada batas-batas kemungkinan seseorang mencapai kebahagiaan hidup di dunia dan akhirat. Dengan tujuan ini, ia menginginkan terbentuknya pribadi yang mempunyai struktur jiwa yang seimbang, serta tidak hanya menekankan pada perkembangan akal, tetapi juga perkembangan spiritual. 
Pendidikan akal ditujukan sebagai alat untuk menanamkan kebiasaan berfikir dan dapat membedakan antara yang baik dengan yang buruk, antara yang berguna dengan yang membawa kemelaratan diri. Di samping pendidikan akal, ia pun mementingkan pendidikan spiritual. Artinya, ia tidak hanya mengharapkan lahirnya generasi yang mampu berfikir, tetapi juga yang memiliki akhlak yang mulia dan jiwa yang bersih. Pendidikan spiritual diharapkannya moral yang tinggi akan terbentuk, sehingga sikap-sikap yang mencerminkan kerendahan moral dapat terhapuskan.

Dengan demikian, kedua aspek akal dan spiritual menjadi sasaran utama pendidikan. Bila kedua aspek tersebut dididik dengan akhlak agama, maka umat Islam akan dapat berpacu dengan Barat dalam menemukan ilmu pengetahuan baru, dan dapat mengimbangi mereka dalam kebudayaan.

Pendidikan perlu menjadi bekal demi kesiapan manusia untuk memahami keberagaman manifestasi nilai-nilai dalam peri kehidupannya sebagai anggota masyarakat. Kesanggupan untuk memahami keberagaman dalam konteks pendidikan di Indonesia harus sudah mulai dibentuk melalui sistem pendidikan nasional sejak jenjang pendidikan dasar dan berlanjut pada jenjang berikutnya (Wekke \& Mokodenseho, 2018; Wekke et al., 2018). Bentuk penyajiannya tentu disesuaikan dengan tingkat perkembangan anak. Pendidikan tidak hanya terpusat pada usaha pencerdasan logika, tetapi juga pada terbentuknya kepedulian etika dan kepekaan estetika. Upaya peningkatan kesadaran religius bisa ditambahkan sebagaimana berlaku di Indonesia menurut UU Nomor 20 Tahun 2003 tentang Sistem Pendidikan Nasional. Pendidikan melalui upaya dalam lingkungan keluarga juga meliputi usaha sosialisasi yang menyiapkan manusia sebagai warga masyarakat. Perkenalan peserta didik dengan berbagai bidang itu dapat disiapkan sepanjang perjalanan pendidikannya, baik melalui jalur sekolah maupun luar sekolah. Perkenalan dengan berbagai ranah itu memperluas spektrum pilihan bagi peserta didik untuk memiliki nilai yang dijadikan orientasi bagi perkembangan dirinya. Peserta didik harus diperkenalkan ke berbagai bidang. Perkenalan itu akhirnya membuka perspektif bagi seseorang untuk membuat pilihan, apakah ia ingin menjadi homo religiosus, homo aestheticus, homo politicus, homo economicus, atau homo academicus, dan sebagainya.

Azra (1999) menjelaskan bahwa pendidikan Islam mempunyai beberapa karakteristik, yaitu: pertama, penekanan pada pencarian ilmu pengetahuan, penguasaan dan pengembangan atas dasar ibadah kepada Allah SWT. Kedua, pengakuan akan potensi dan kemampuan seseorang untuk berkembang dalam suatu kepribadian, setiap pencari ilmu dipandang sebagai makhluk Tuhan yang perlu dihormati dan disantuni, agar potensipotensi yang dimilikinya dapat teraktualisasi dengan sebaik-baiknya. Ketiga, pengamalan ilmu pengetahuan atas dasar tanggungjawab kepada Tuhan dan masyarakat manusia. Di sini pengetahuan bukan hanya untuk diketahui dan dikembangkan, melainkan sekaligus dipraktekkan dalam kehidupan nyata. Dengan demikian terdapat konsistensi antara apaapa yang diketahui dengan pengamalannya dalam kehidupan sehari-hari.

Dinamika kehidupan manusia mesti merujuk pada ajaran agama. Berbagai pendidikan di Indonesia memiliki prinsip dasar yang tertera dalam Al-Quran dan Sunah. Kaidah-kaidah agama tidak sekedar menjadi pewarna, tetapi merupakan sumber inspirasi dan melandasi setiap aktivitas dan derap kehidupan manusia. Sebagai agama terakhir, Islam menawarkan sekian prinsip mulia yang terkait dengan pendidikan. Misalnya dalam QS. Al-Alaq (96), secara implisit mengajarkan prinsip-prinsip pendidikan dalam meningkatkan kedisiplinan dalam etika perburuan ilmu pengetahuan dan teknologi dalam peningkatan etos kerja. QS. Al-Alaq (96): 1-5 adalah wahyu pertama yang diturunkan Allah SWT. kepada Nabi Muhammad SAW. Wahyu pertama tersebut tidak hanya menandakan bahwa Nabi sebagai Rasul Allah, tetapi juga sebagai siswa yang dididik oleh Allah SWT. dan menjadi pendidik bagi seluruh umat manusia. Wahyu pertama ini berisi teori inti desain 
pembelajaran (Anam \& Fikroni, 2020). Oleh karena itu, konsep dasar dan desain pembelajaran pendidikan tentang ketuhanan memiliki beberapa implikasi yang dapat diaktualisasikan dalam konteks pendidikan Islam di abad ini, di antaranya pendidikan tentang ketuhanan berakhir pada puncak misi kehidupan, yakni keilahian (monoteisme), kemudian pendidikan tentang ketuhanan yang telah dilalui oleh Nabi Muhammad SAW. adalah cerminan dari proses pendidikan Islam yang ideal.

Selain itu, melalui wahyu sebagaimana disebutkan di atas, Allah SWT. mengajak dialog kepada manusia untuk membaca alam semesta, diri manusia dan lingkungan sekitarnya yang mencakup berbagai aspek kehidupan, yakni pendidikan, sosial, politik, ekonomi dan budaya. Fadjar (1999) mengatakan manusia yang berkualitas menurut AlQuran, paling tidak bertumpu pada tiga indikator, yakni berkualitas dalam berfikir, berkualitas dalam berzikir, dan berkualitas dalam berkarya (beramal).

Ashraf (1985) menyatakan bahwa manusia dalam Islam dianggap sebagai wakil Tuhan di bumi dan seluruh ciptaan lainnya tunduk kepada manusia. Dengan kebesaranNya, Tuhan menciptakan segalanya dari tiada menjadi ada. Menurut Al-Quran, Tuhan adalah awal dan akhir, satu-satunya Yang Maha Kuasa pada awalnya yang hingga akhirnya tetap satu juga. Kesatuan itulah yang menjadi kekuatan di alam ini dan itulah yang dijadikan potensi untuk membangun peradaban manusia.

Dalam proses pendidikan untuk memulai segala sesuatu diawali dengan ketidaktahuan, sebagaimana Nabi Muhammad SAW. pertama kali menerima wahyu. Kemudian secara bertahap dapat mengetahui segala sesuatu sesuai dengan usahanya dan itu melalui guru (Jibril) sebagai medium pengajaran (Amir MZ et al., 2019). Dengan proses pendidikan tersebut dalam konteks kekinian dilakukan melalui lembaga pendidikan sehingga dapat terukur pada proses pendidikannya.

Pendidikan Islam memberi semangat untuk selalu menuntut ilmu dari manapun juga. Nabi Muhammad SAW. secara simbolik menyampaikan pesan edukasi untuk mencari ilmu walaupun di negeri Cina (uthlub al-'ilm wa lau bi al-shin). Di lain sisi, QS. Al-Ashr (103) menunjukkan betapa penting dan mahal waktu bagi manusia. Allah SWT. mengawali surat tersebut dengan sumpah wa al-Ashri (demi masa), kemudian diteruskan dengan penegasan kelompok manusia yang tidak beruntung. Kecuali orang-orang yang beriman dan beramal saleh, serta mereka yang terbiasa dengan budaya kritik dan evaluasi dalam kebenaran dan kesabaran. Sumpah Allah SWT. tentang betapa mahalnya waktu menunjukkan bahwa ukuran kesuksesan manusia ditentukan dengan kecerdasan mempergunakan dan mendayagunakan waktu. Maka dari itu, adalah sebuah kewajiban kita semua untuk memaksimalkan waktu secara efektif dan efisien, serta meyakini bahwa orang-orang yang memanfaatkan waktu dengan sebaik-baiknya adalah orang-orang yang beruntung.

\section{Pendidikan Islam Progresif: Orientasi Wawasan, Sikap dan Tindakan}

Orientasi umat Islam selama berabad-abad menguasai dunia tidak pernah terpisahkan dari yang namanya "semangat kompetisi positif/berlomba-lomba dalam kebaikan" (QS. Al-Baqarah (2): 148, "budaya kritik konstruktif", dan "pendidikan yang membebaskan". Masa kejayaan yang di kenyam umat Islam tidak terbatas pada periode maupun geografis tertentu.

Masa kejayaan yang di kenyam umat Islam melibatkan beberapa periode dan mencakup banyak kawasan. Fadjar (1983) mengutip pandangan al-Tawaijri mengatakan masa keemasan itu terbagi atas tiga tahapan; Pertama, masa Nabi Muhammad SAW. Masa ini ditandai dengan kemerdekaan merumuskan pemikiran-pemikiran aktual dan kontekstual atas dasar Al-Quran dan Sunah. Semangat intelektual ini kemudian dikenal dengan sebutan ijtihad yang dirumuskan sebagai upaya maksimal setiap Muslim merumuskan keputusan atau stimulant hukum dari dua sumber ajaran Islam, yakni Al- 
Quran dan Sunah. Kedua, masa penafsiran perorangan dan kolektif yang menjamur setelah meninggalnya Nabi Muhammad SAW. Kelompok-kelompok suku di Madinah terlibat dalam perdebatan yang panas tentang berbagai persoalan. Masalah hukum yang bermuara pada persoalan politik kemudian tercatat sebagai tema sentral yang paling dominan. Pergumulan pemikiran yang semakin mewarnai dinamika umat Islam ditandai dengan kehadiran para cendikiawan Muslim (ulama) yang menggantikan posisi dan peran Nabi dalam menyebarluaskan ajaran Islam. Meski tidak terhindar dari friksi-friksi yang terlibat dalam perselisihan politik dan pertikaian fisik, namun secara umum mereka merujuk kepada semangat Islam yang membolehkan berbeda pendapat antara satu dengan yang lainnya. Ketiga, keterpanggilan cendikiawan Muslim untuk memadukan ilmu pengetahuan dan teknologi (sains) dengan ajaran Islam. Peran cendekiawan Muslim sangat dibutuhkan karena mengingat saat ini globalisasi memberi dampak besar pada dunia, termasuk pendidikan Islam (Buto \& Hafifuddin, 2019; Nawi et al., 2012). Tidak hanya itu, globalisasi berdampak besar pada arus pertumbuhan dan perkembangan Teknologi Informasi dan Komunikasi (TIK) yang cepat (Idris et al., 2020). Kemajuan ini membuka ruang dan kesempatan bagi lembaga pendidikan Islam untuk menyesuaikan dengan berbagai media yang bermanfaat untuk mencapai tujuan, serta menerapkan pengajaran dan pembelajaran pendidikan Islam secara efektif.

Dengan demikian, kaitannya dengan prestasi dan pencapaian yang dimiliki oleh umat Islam, semuanya itu tidak terlepas dari wawasan, sikap dan tindakan keagamaan yang dimiliki oleh kaum Muslim itu sendiri.

Orientasi wawasan, sikap dan tindakan keagamaan umat Islam tercermin dalam pandangan mereka terhadap beberapa hal sebagai berikut;

Pertama, alam semesta. Pandangan Islam tentang alam berbeda dengan pandangan filsafat idealisme ataupun materialisme. Filsafat idealisme yang mengatakan bahwa dunia materi atau alam ini tidak riil, yang sebenarnya dalam kenyataan ialah ide, kesadaran dan sebagainya. Sementara ini tidak lain adalah bayang-bayang pancaran atau gambaran dari dunia ide (Fadjar \& Ghofir, 1981). Berbeda dengan pandangan Islam, yang meyakini bahwa alam adalah sesuatu ciptaan Tuhan secara sengaja sehingga wujud alam adalah nyata dan kongkrit (Bacik, 2020) sebagaimana dalam QS. Ibrahim (14): 19. Di dalam ayat tersebut mengandung arti bahwa Tuhan menjadikan semua (langit dan bumi) bukanlah dengan percuma, melainkan dengan penuh hikmah. Selain itu, Tuhan menetapkan alam dengan hukum-hukum dan pola-pola yang tidak berubah atau sudah menjadi ketetapan Tuhan (sunatullah).

Kedua, hakikat manusia. Manusia sebagai salah satu makhluk ciptaan Tuhan telah mengundang untuk menjadi sarana studi atau pembicaraan yang menarik, baik dari sudut ilmu pengetahuan maupun agama. Namun, pembicaraan itu tidak pernah selesai dan secara tuntas memperoleh kesimpulan yang tepat mengenai keseluruhan aspek manusia. Begitulah seterusnya, manusia tetap menjadi objek yang menarik, yang tidak ada habishabisnya sepanjang zaman, dan tetap akan menempati pandangan yang unik. Nilai yang unik tersebut terletak pada pengembangan intelektual bermuara pada tujuan esensial dari pendidikan.

Ada beberapa pandangan Islam tentang manusia, yaitu: (1) manusia adalah ciptaan Tuhan yang tertinggi, paling sempurna dan merupakan makhluk yang paling unik yang merupakan puncak dari ciptaannya; (2) manusia berkemauan bebas, artinya berbeda dengan makhluk lainnya karena ia dilengkapi dengan akal pikiran yang melahirkan kemampuan untuk berfikir dan menentukan sikap. Kemauan bebas (free will) itu antara lain yang terdapat pada manusia dalam menghadapi hukum-hukum dan ketentuanketentuan Tuhan bagi manusia sehingga memungkinkan mereka ada yang tunduk dan patuh (Muslim) dan ada yang ingkar (kafir); (3) manusia diciptakan untuk mengabdi 
kepada Tuhan. Keempat, manusia itu bersifat hanif artinya menurut kodratnya ia condong, mencari dan memihak kepada kebenaran. Hal ini sesuai dengan fitrah atau kejadian asal yang bersifat suci. Kelima, manusia adalah khalifah atau wakil Tuhan di muka bumi, artinya bahwa manusia ditugaskan oleh Tuhan untuk menggarap dan mengolah masalah dunia karena dunia ini dijadikan untuk kepentingannya. Amanat ini kemudian akan dipertanggungjawabkan kepada Tuhan dalam pelaksanaannya. Keenam, individu manusia adalah suatu kenyataan, artinya bahwa tiap-tiap dari individu manusia bertanggungjawab atas segala perbuatannya, baik ataupun buruk (Zahrin et al., 2019; Abdullah et al., 2019).

Mengetahui pandangan tentang hakikat manusia itu sangat penting, terutama dalam rangka mengenal Tuhan selaku penciptanya, seperti yang diungkapkan para ahli tentang ketuhanan bahwa "barang siapa yang mengenal dirinya sendiri, maka ia akan dapat mengenal Tuhannya". Juga dalam Al-Quran, Tuhan menyampaikan pesannya agar manusia mengenal dirinya.

Ketiga, Islam sebagai sumber ajaran. Islam sebagai agama mengandung nilai-nilai ajaran yang sejalan dengan fitrah manusia, artinya bahwa ajaran-ajaran Islam itu sejalan dengan kejadian alamiah manusia dan sekaligus merupakan kewajiban atas pertanyaan manusia yang ada secara fitriah tentang bagaimana dan untuk apa sebenarnya manusia ini hidup, itulah sebabnya.

Pada hakikatnya adanya Islam tidak lain adalah sebagai pemenuhan janji Tuhan bahwa Dia akan memberikan petunjuk kepada manusia tentang tugas manusia dalam menempuh hidupnya secara wajar sehingga sejalan dan serasi dengan alam di sekitarnya. Dalam Al-Quran, Tuhan berfirman sekitar peristiwa turunnya Adam dan Hawa (manusia) ke dunia. Janji itu perlu diberikan karena manusia tidak mungkin dibiarkan mencari-cari jalannya sendiri untuk menemukan hukum-hukum objektif tentang hidup dan kehidupannya.

Keempat, agama dan ilmu pengetahuan. Agama pada umumnya berisi ajaran-ajaran yang diyakini turun kepada manusia melalui wahyu dalam arti bahwa ajaran-ajaran itu berasal dari Tuhan dan oleh karena itu bersifat benar, dan tidak akan berubah-ubah sekalipun kondisi manusia berubah mengikuti zaman. Ajaran-ajaran agama itu bersifat absolut, tidak akan berupah dan tidak akan dapat dirubah menurut peredaran masa, ia merupakan dogma. Inilah yang menimbulkan sikap dogmatis dalam tiap agama.

Ilmu pengetahuan sebaliknya tidak kenal dan tidak terikat pada waktu. Ilmu pengetahuan berpijak dan terikat pada pemikiran rasional. Itulah sebabnya secara populer orang mengatakan bahwa agama bermula dari tidak percaya. Akan tetapi, meskipun titik berangkatnya berbeda, tidak berarti bahwa antara agama dan ilmu itu berada dalam posisi yang bertentangan. Kalau agama mempunyai nilai kebenaran yang mutlak, maka ilmu yang sifat kebenarannya relatif merupakan alat bagi manusia untuk mencari dan menemukan kebenaran-kebenaran itu. Dengan menggunakan kekuatan daya pikir dan dengan bimbingan hati nuraninya, manusia dapat menemukan kebenaran-kebenaran dalam hidupnya secara baik, yaitu beramal saleh. Dengan kata lain, ilmu pengetahuan adalah persyaratan dari amal saleh (Fadjar \& Ghofir, 1981).

Sejalan dengan itulah Islam memandang kegunaan dan peranan ilmu, sehingga tidak membuat garis pemisah antara agama dan ilmu pengetahuan (Gingras, 2018; Lyons, 2012). Keterpaduan agama dan ilmu pengetahuan menjadikan manusia betapapun tinggi derajat keilmuannya, selalu bertanggungjawab. Karena akal semata tidak selalu membimbing ke jalan yang benar. Salah satu ciri akal adalah juga kemungkinannya untuk menyesatkan, dan bahkan menimbulkan kerumitan bagi manusia itu sendiri. Diterangi oleh nilai-nilai agama, maka proses akal tidak akan terbiarkan menyusuri garis-garis yang menyesatkan. Tidak terpisahnya agama dan ilmu berarti pula berpadunya hati nurani (conscience) dan pengetahuan (science). Oleh karena itu, dapat dipahami mengapa Islam menganggap 
perlunya integrasi agama dan ilmu, sekaligus menempatkan orang-orang yang beriman dan berilmu pada posisi yang lebih tinggi sebagaimana yang terdapat dalam QS. AlMujadilah (58): 11. Agama adalah nilai-nilai panutan yang memberi pedoman pada tingkah laku manusia dan pandangan hidupnya; ilmu adalah hasil yang dicapai oleh manusia berkat kemampuannya sebagai anugerah dari Tuhan. Ilmu tidak dibekalkan sebagai barang instan tetapi harus dicari dengan cara belajar yang tekun dan sabar. Dalam ikhtiar mencari ilmu pengetahuan, Tuhan membekali manusia dengan berbagai kemampuan yang memang kodratnya sesuai dengan keinginan untuk mengetahui apa saja, terutama hal-hal positif yang belum diketahuinya.

Dengan demikian, kerja ilmu pengetahuan bukan sekadar dimaksudkan untuk membaca hasil ciptaan Allah secara deskriptif, semata-mata diletakkan sebagai obyek ilmu, apalagi seperti paradigma keilmuan modern yang menolak penjelasan metafisis dan filosofis terhadap alam kosmik, tetapi lebih dari itu, ilmu pengetahuan perlu diarahkan secara teologis dan sosiologis atau zikir dan fikir untuk membangun hubungan yang lebih dekat antara manusia dengan Allah sebagai sumber pengetahuan, serta untuk membantu manusia menjalankan tugas dan fungsinya sebagai khalifah di muka bumi.

Kaitannya dengan model pendidikan Islam progresif, pendidikan Islam harus diarahkan pada upaya untuk mempertajam dan memperkuat potensi zikir (sains) dan fikir (teknologi) peserta didik, sehingga akan terwujud manusia yang berwawasan modern dan berjiwa pembaru. Kesadaran akan kelemahan yang ada dalam dirinya kemudian berupaya meningkatkan potensi dalam dirinya dan menjalin hubungan secara harmonis dan humanis serta membesarkan dan menguatkan orang lain, maka ia akan menjadi orang yang terbaik (khaira ummah). Sebaliknya, seseorang yang tidak mampu mengendalikan hawa nafsunya dan merasa benar sendiri, serta melemahkan orang lain, hanya akan menjadikan dirinya lemah dan termasuk ke dalam golongan asfala safilin. Hal yang membedakan antara khaira ummah dan asfala safilin adalah ilmu pengetahuan.

\section{KESIMPULAN}

Pendidikan Islam harus berorientasi dan diarahkan pada pemberdayaan manusia. Pendidikan yang berorientasi pada pemberdayaan manusia hanya bisa dilakukan dengan membuat model pendidikan yang progresif. Model pendidikan ini dapat menjadi alternatif solusi dari ketertinggalan pendidikan Islam dan sikap umat Islam selama ini, yang ditimbulkan oleh sistem dan hukum kehidupan yang kerap berseberangan dengan apa yang diharapkan oleh umat dan pendidikan itu sendiri. Agar nilai esensial dari pendidikan Islam itu selalu terjaga, adalah sebuah keharusan untuk mengembangkan potensi manusia, baik dari segi wawasan, sikap maupun tindakan, demi mempertahankan hak-haknya, serta pendidikan Islam dapat memastikan bahwa manusia terus memperoleh hak-haknya secara adil sesuai fitrahnya, dan terhindar dari kekuatan-kekuatan yang dapat memengaruhinya. Selain itu, pendidikan Islam harus diarahkan pada pembentukan watak manusia sebagai khalifah yang memiliki wawasan potensial dalam pengembangan peradaban manusia. Setiap tindakan selalu didasarkan kepada tauhid sebagaimana diyakini oleh setiap Muslim bahwa Islam adalah agama terakhir, dan sebagai rahmat bagi seluruh alam, yaitu terciptanya tatanan dunia yang dinamis, harmonis dan lestari. Sehingga dengan misi tersebut, seluruh penghuninya, baik manusia maupun makhluk lain merasa aman dan nyaman di dalamnya. Model pendidikan Islam yang progresif lebih ditekankan pada pengembangan potensi kualitas Sumber Daya Manusia (SDM) yang kompetitif dan produktif. Dengan kuatnya kualitas dan potensi pribadi manusia, khususnya kualitas dan potensi umat Muslim, membuat mereka mampu menyadari dan mendalami makna pendidikan Islam dalam kehidupan untuk menentukan jati diri yang lebih baik. 
Argumentasi yang dapat dikemukakan dan sebagai saran untuk perbaikan pendidikan Islam ke depan, di antaranya: perlu ditinjau kembali sistem pendidikan Islam yang saat ini berjalan dengan tetap mengedepankan spirit dan ajaran Islam; mempersiapkan SDM yang berkualitas dengan bekal kemampuan yang komprehensif; menegaskan kembali peran semua elemen dalam pendidikan, yaitu individu, keluarga, masyarakat, lembaga pendidikan, dan negara; menyatukan iman dan takwa (imtaq) dengan ilmu pengetahuan dan teknologi (iptek) sebagai dasar kekuatan menghadapi tantangan zaman yang semakin kompleks; membangun jaringan pendidikan dari skala lokal, nasional, dan global sebagai bentuk komunikasi aktif dalam merespon perkembangan pendidikan Islam; serta, memelihara dan menjaga potensi budaya lokal masyarakat sekaligus sebagai jembatan komunikasi budaya dengan tetap berpegang pada semangat keislaman.

\section{DAFTAR PUSTAKA}

Abd, A. A. 2020. Evaluation of Holy Quran \& Islamic Education Curriculum of Second Intermediate Stage from Perspectives of Teachers \& Supervisors of the Material: A Field Study conducted in the Directorates-General of Education in Baghdad Governorate. Journal of College of Education for Women, 31(1), 83-99. https://doi.org/10.36231/coedw/vol31no1.6

Abdullah, A., Masruri, S., \& Bashori, K. 2019. Islamic Education and Human Construction in The Quran. International Journal of Education and Learning, 1(1), 27-32. https://doi.org/10.31763/ijele.v1i1.21

Abdullah, M. 2019. School Culture to Serve Performance of Madrasah in Indonesia. QIJIS (Qudus International Journal of Islamic Studies), 7(1), 71. https://doi.org/10.21043/qijis.v7i1.4809

Abdullah, M. A. 2017. Islamic studies in higher education in Indonesia: Challenges, impact and prospects for the world community. Al-Jami'ah, 55(2), 391-426. https://doi.org/10.14421/ajis.2017.552.391-426

Ahmadi, A. 2017. Descriptive-Analytical Studies of Literacy Movement in Indonesia, 20032017. International Journal of Humanities and Cultural Studies, 4(3), 16-24. https://www.ijhcs.com/index.php/ijhcs/article/view/3141

Akbar, R. N., Sugiyanto, S., \& Doewes, M. 2020. The Physical Education in Darul Ulum Islamic Boarding School. AESA: Asian Exercise and Sport Science Journal, 4(1), 40-44. https://doi.org/10.30472/aesj.v4i1.106

Al-Abrasyi, M. A. 1969. Al-Tarbiyah al-Islamiyah wa Falsafatuha. Kairo: Isa al-Babi al-Halabi. Al-Kailani, M. I. 1988. Falsafat al-Tarbiyah al- Islamiyah. Mekah: Maktabah Hadi.

Al-Nahlawi, A. 1996. Ushul al-Tarbiyah al- Islamiyah fi al-Bait wa al-Madrasah wa alMujtama'. Damaskus: Dar al-Fikr.

Alayoubi, M. M., Al Shobaki, M. J., \& Abu-Naser, S. S. 2020. Strategic Leadership Practices and their Relationship to Improving the Quality of Educational Service in Palestinian Universities. International Journal of Business Marketing and Management, 5(3), 11-26. www.ijbmm.com

Amir MZ, Z., Risnawati, R., \& Muhandaz, R. 2019. Konsep Sunnah dalam Pembelajaran Sains. Journal of Natural Science and Integration, 1(2), 185-194. https://doi.org/10.24014/jnsi.v1i2.6597

Anam, N., \& Fikroni, M. R. 2020. Rabbani Education: Basic Concepts, Design and Implications of Rabbani Education Learning. Tribakti: Jurnal Pemikiran Keislaman, 31(1), 67-82.

https://ejournal.iai-tribakti.ac.id/index.php/tribakti/article/view/975/600

Ashraf, A. 1985. New Horizons in Muslim Education. Cambridge: Antony Rowe Ltd. 
Azis, A. 2016. A Step Ahead Education (Human Potential Development Oriented). International Seminar on Education, 36-44. http://seminar.umpo.ac.id/index.php/ISE2016/article/view/415

Azman, Z., \& Helandri, J. 2020. Islamic Education for Millennial Era Generations. Proceeding ISID, 1, 296-317. https://doi.org/10.37092/PROSIDINGISID.V1I1.197

Azra, A. 1999. Pendidikan Islam Tradisi dan Modernisasi Menuju Milenium Baru. Jakarta: PT. Logos Wacana Ilmu.

Azra, A. 2002. Paradigma Baru Pendidikan Nasional Rekonstruksi dan Demokratisasi. Jakarta: Kompas.

Bacik, G. 2020. The Islamic Idea of Nature in Contemporary Turkey. In Islam and Muslim Resistance to Modernity in Turkey. Cham: Palgrave Macmillan.

Bashori, B., Prasetyo, M. A. M., \& Susanto, E. 2020. Change Management Transfromation in Islamic Education of Indonesia. Social Work and Education, 7(1), 72-85. https://doi.org/10.25128/2520-6230.20.1.7.

Bensaid, B., \& Machouche, S. 2020. Education Piety: Special Reference to Abu Hamid alGhazali and Abdul Rahman Ibnu Khaldun. Global Perspectives on Teaching and Learning Paths in Islamic Education, 34-59. https://doi.org/10.4018/978-1-52258528-2.ch003

Buto, Z. A., \& Hafifuddin, H. 2019. Swot Analysis of Islamic Education Facing the Era of Globalization. International Journal of Innovation, Creativity and Change, 9(4), 305312. https://www.ijicc.net/images/vol9iss4/9421_Buto_2019_E1_R1.pdf

Das, S. W. H., Halik, A., \& Amaluddin, A. 2016. Paradigm of Islamic Education in the Future: The Integration of Islamic Boarding School and Favorite School. Information Management and Business Review, 8(4), 24-32. https://doi.org/10.22610/imbr.v8i4.1390

Fadjar, A. M. \& Ghofir, A. 1981. Pendidikan Islam di Perguruan Tinggi. Surabaya: Lembaga Penerbitan Universitas Brawijaya Malang.

Fadjar, A. M. 1983. Kata Pengantar dan Editor "Islam dan Dinamika Kebebasan Akademi." In A. O. Altawaijri (Ed.), Academic Freedom Islam and The West: A study of the Philosophical Foundations of Academik Freedom in Islam, terj. Mufid, Islam dan Kebebasan Akademi. Malang: Citra Mentari Group.

Fadjar, A. M. 1999. Sambutan pada Acara Pembukaan Madrasah Terpadu YASUCI Cijantung 14 Mei 1999. In Himpunan Pidato Menteri Agama RI. Tahun 1999. Biro Hukum dan Humas Sekretaris Jenderal Depag RI.

Fadjar, A. M. 2006. Pengembangan Pendidikan Islam yang Menjanjikan Masa Depan. In H. Esa, M. I., \& Syaifuddin (Ed.), Kumpulan Orasi Ilmiah Pengukuhan Guru Besar UIN Malang Periode 1989-2006. Malang: UIN Malang Press.

Fahriana, A. S., \& Huda, M. 2019. Application of Analysis of Strengths, Weaknesses, Opportunities, and Threats in Islamic Education Institutions. ISTAWA: Jurnal Pendidikan Islam (IJPI), 4(1), 52-64. https://doi.org/10.24269/ijpi.v4i1.1670

Fajariah, M., \& Suryo, D. 2020. Teacher's Education for Character Education. Proceedings of the 2nd International Conference on Social Science and Character Educations (ICoSSCE 2019), 311-320. https://doi.org/10.2991/assehr.k.200130.063

Flick, U. 2018. An Introduction to Qualitative Research (6th ed.). SAGE Publications Ltd.

Gingras, Y. 2018. Religion and Science. Issues in Science and Technology, 34(2), 17-18. http://www.jstor.org/stable/44577397

Gunawan, I., Ahmadi, F., \& Dukuhwaluh, R. 2020. Implementation of Character Education for Elementary Students. Journal of Primary Education, 9(2), 168-175. https://doi.org/10.15294/jpe.v9i2.36646

Hamka. 1962. Lembaga Hidup. Jakarta: Djajamurni. 
Muh. Idris, dkk.: Model Pendidikan Islam Progresif

Ibrahim, M. A. 2019. Earth's Formation from The Quranic Perspectives Based on Surah AlRa'd Verse 3. IJASOS- International E-Journal of Advances in Social Sciences, 5(15), 1321-1326. https://doi.org/10.18769/ijasos.592099

Idris, M., Willya, E., Wekke, I. S., \& Mokodenseho, S. 2020. Peace Resolution in Education and Application on Information and Communication Technologhy. International Journal of Advanced Science and Technology, 29(6), 3349-3358. http://sersc.org/journals/index.php/IJAST/article/view/14076

Jackson, S. L. 2015. Research Methods and Statistics: A Critical Thinking Approach (5th ed.). Cengage Learning.

Kalaian, S. A., Kasim, R. M., \& Kasim, N. R. 2019. Descriptive and Predictive Analytical Methods for Big Data. In Web Services (pp. 314-331). IGI Global. https://doi.org/10.4018/978-1-5225-7501-6.ch018

Kotsonis, A. 2020. What can We Learn from Plato about Intellectual Character Education? Educational Philosophy and Theory, 52(3), 251-260. https://doi.org/10.1080/00131857.2019.1631157

Lafmejani, A. Q. 2020. The Human in the perspective of Freud and its comparison with the Shiite Islam perspective. Technium Social Sciences Journal, 4(1), 84-93. https://doi.org/10.47577/tssj.v4i1.65

Lisaldi, J. \& Lisa, E. N. 2019. Islamic educational thoughts of ibn al-Qayyim al-Jauziyah and Syed Muhammad Naquib al-Attas as a Science and Islamic integration method. In N. A. Rahman, S. A. Said, F. N. M. Zabidi, \& A. N. A. Rahman (Eds.), 10Th International Symposium on Islam, Civilization and Science (pp. 35-43). Universiti Kebangsaan Malaysia.

Lovat, T. 2020. Islamic education today and yesterday: Principal themes and their potential to enlighten Western education. Global Perspectives on Teaching and Learning Paths in Islamic Education, 1-19. https://doi.org/10.4018/978-1-5225-8528-2.ch001

Lyons, J. 2012. Islam and Science. In Islam Through Western Eyes: From the Crusades to the War on Terrorism. New York: Columbia University Press.

Mahfud, C. 2020. Understanding Political Reform and Islamic Education Position in Indonesia. AL-MURABBI: Jurnal Studi Kependidikan Dan Keislaman, 6(2), 130-136. http://ejournal.kopertais4.or.id/mataraman/index.php/murabbi/article/view/3768

Mahmood, S. K. 2019. Factors Affecting Learning Islamic Science in Developing Countries. International Journal of Rural Development, Environment and Health Research, 3(5), 168-176. https://doi.org/10.22161/ijreh.3.5.3

Manan, A. 2020. Islamic Educational Values in Life-Cycle Rituals: An Ethnographic Study in Kluet Timur Community, Aceh, Indonesia. In Global Perspectives on Teaching and Learning Paths in Islamic Education (pp. 118-134). https://doi.org/10.4018/978-15225-8528-2.ch007

Mann, T. 2015. The Oxford Guide to Library Research (4th ed.). Oxford University Press.

Mansir, F., \& Karim, A. 2020. Islamic Education Learning Approaches in Shaping Students' Emotional Intelligence in the Digital Age. Hayula: Indonesian Journal of Multidisciplinary Islamic Studies, 4(1), 67-86. https://doi.org/10.21009/004.01.04

Marimba, A. D. 1989. Pengantar Filsafat Pendidikan Islam. Bandung: Al-Ma'arif.

Merriam, S. B., \& Tisdell, E. J. 2016. Qualitative Research: A Guide to Design and Implementation (4th ed.). Jossey-Bass, Inc.

Mokodenseho, S., \& Wekke, I. S. 2017. Toleransi Beragama dan Pembelajaran Agama Islam: Harmoni Masyarakat Minoritas Muslim Manado. Proceeding: Seminar Nasional \& Temu $\begin{array}{llll}\text { Ilmiah Jaringan } & \text { (2017), }\end{array}$ http://ejournal.iaida.ac.id/index.php/proceeding/article/view/131

Nawi, M. A. M., Jamsari, E. A., Hamzah, M. I., Sulaiman, A., \& Umar, A. 2012. The Impact of 
Globalization on Current Islamic Education. Australian Journal of Basic and Applied Sciences, 6(8), 74-78. www.alexa.com

Okros, A. 2020. Education and Learning. In Harnessing the Potential of Digital PostMillennials in the Future Workplace (pp. 53-72). https://doi.org/10.1007/978-3-03025726-2_3

Paulussen, C., \& Scheinin, M. 2019. Human Dignity and Human Security in Times of Terrorism. In Human Dignity and Human Security in Times of Terrorism. T.M.C. Asser Press. https://doi.org/10.1007/978-94-6265-355-9

Rabilla, A., \& Nurhayati, N. 2020. Strategies of Islamic Education in The Perspective of the Qur'an. Proceeding International Seminar of Islamic Studies, 1(1), 641-646. http://jurnal.umsu.ac.id/index.php/insis/article/view/4200

Setiawan, W. 2020. The Spiritual Education Toward Insan Kamil in The Education of Modern Humankind. International Seminar on Education, 478-483. http://seminar.umpo.ac.id/index.php/ISE2016/article/view/498

Sheikh, S. U., \& Ali, M. A. 2019. Al-Ghazali's Aims and Objectives of Islamic Education. Journal of Education and Educational Development, 6(1), 111-125. https://eric.ed.gov/?id=EJ1216762

Sugiana, A. 2019. Islamic Education Perspective Imam al-Ghazali and Its Relevance with Education in Indonesia. Jurnal Tarbiyah, 26(1), 81-94. https://doi.org/10.30829/tar.v26i1.400

Suminto, S. 2019. Psychological Principle and Its Implications in Islamic Education Hasan Langgulung's Perspective. AL-HAYAT: Journal of Islamic Education, 3(2), 224-236. https://doi.org/10.35723/ajie.v3i2.79

Suri, E. M., Marmai, U. A. O., \& Silalahi, J. 2019. Curriculum Development in West Sumatra Context of The Historical Perspectives and The Implementation. Proceedings of the 1st International Conference on Innovation in Education (ICoIE 2018), 137-140. https://doi.org/10.2991/icoie-18.2019.32

Syukri, M. 2019. Modernization of Indonesian Islamic Education Critical Study on Madrasah Human Resources Development. Hijri, 8(1), 1-24. http://jurnal.uinsu.ac.id/index.php/hijri/article/view/5811

Ulgen, 0. 2020. Human Dignity in an Age of Autonomous Weapons: Are We in Danger of Losing an 'Elementary Consideration of Humanity'? Baltic Yearbook of International Law Online, 17(1), 167-196. https://doi.org/10.1163/22115897_01701_009

Watts, J., \& Mahfood, S. 2014. Assessing Library Research Consultations: A Mixed-Method Approach. In S. Durso, S. Hiller, M. Kyrillidou, \& A. Pappalardo (Eds.), Proceedings of the 2014 Library Assessment Conference: Building Effective, Sustainable, Practical Assessment (pp. 583-589). Association of Research Libraries.

Wekke, I. S., \& Mokodenseho, S. 2017. Religious teaching and learning in minority Muslim of Manado Indonesia. 2nd International Conference on Education, Science, and Technology (ICEST 2017), 187-189. https://doi.org/10.2991/icest-17.2017.62

Wekke, I. S., \& Mokodenseho, S. 2018. Tolerance, Understanding, and Religious Teaching and Learning in Minority Muslim of Manado North Sulawesi. https://doi.org/10.31227/osf.io/hjzmc

Wekke, I. S., Mokodenseho, S., \& Rahman, A. F. 2018. Values of Religious Tolerance in Islamic Learning Material of Muslim Minority State High School. https://doi.org/10.31227/osf.io/tfbkc

Yahya, W. Bin, \& Rahmat, M. 2019. The Characteristics of Muttaqin in the Qur`an and its Implication on the Aim of Islamic Education. Proceedings of the Social and Humaniora Research Symposium (SoRes 2018), 296-299. https://doi.org/10.2991/sores18.2019.69 
Muh. Idris, dkk.: Model Pendidikan Islam Progresif

Zahrin, S. N. A., Hasan, S. A., \& Samsudin, M. Z. 2019. Human Capital Transformation As Mediator Between Love for Knowledge and Excellent Muslim. Asean Journal of Teaching and Learning in Higher Education (AJTLHE), 11(2), 1-16. https://ejournal.ukm.my/ajtlhe/article/view/37039 